\title{
Air permeability and sound absorption coefficient changes from ultrasonic treatment in a cross section of Malas (Homalium foetidum)
}

\author{
Chun-Won Kang ${ }^{1}$, Eun-Suk Jang ${ }^{1}$, Nam-Ho Lee ${ }^{2^{*}}$ (D), Sang-Sik Jang ${ }^{3}$ and Min Lee ${ }^{4}$
}

\begin{abstract}
We investigated the effect of ultrasonic treatment on Malas (Homalium foetidum) gas permeability and sound absorption coefficient using the transfer function method. Results showed a longitudinal average Darcy permeability constant of 2.02 (standard deviation SD 0.72) for untreated wood and 6.15 (SD 3.07) for ultrasound-treated wood, a permeability increase of 3.04 times. We also determined the average sound absorption coefficients in the range of 50 to $6.4 \mathrm{kHz}$ and NRC (noise reduction coefficient: average value of sound absorption coefficient value at 250, 500, 1000, and $2000 \mathrm{~Hz}$ ) of untreated Malas. Those values were 0.23 (SD 0.02) and 0.13 (SD 0.01), respectively, while those of ultrasonic-treated Malas were 0.28 (SD 0.02) and 0.14 (SD 0.02), a 19.74\% increase in average sound absorption coefficient.
\end{abstract}

Keywords: Sound absorption coefficient, Transfer function method, Gas permeability, Ultrasonic treatment, Malas

\section{Introduction}

Wood permeability greatly influences drying characteristics [1], chemical impregnation [2-4], and sound absorption in the longitudinal direction [5, 6]. Kanagawa et al. reported that steam explosion treatments improve wood's permeability and drying rates [7]. Various researchers have reported that improving gas permeability increases the ability to treat wood chemically [2-4].

Jang et al. classified three kinds of yellow poplar wood's pore shapes, through pore, blind pore, and closed pore, and measured their contents [8]. In the same way, Jang et al. investigated the pore shapes of three species of conifer (hinoki, Douglas fir, and hemlock) [9]. Permeability increases were affected by pore size and through pore content $[8,9]$. Jang and Kang also used heat treatment to investigate changes in gas permeability, pore size, and pore shape [10]. As the heat treatment temperature increased, pore size and through pore porosity increased,

\footnotetext{
*Correspondence: enamho@jbnu.ac.kr

${ }^{2}$ Department of Wood Science \& Technology, College of Agriculture \& Life Sciences, Jeonbuk National University, Jeonju 54896, South Korea Full list of author information is available at the end of the article
}

which, in turn, caused an increase in gas permeability [10].

In previous research, Kang et al. reported that delignification treatment using Wise's method improved Larix kaempferi's permeability and the cross-sectional surface sound absorption coefficient [11]. Permeability also improved after low-pressure steam explosion treatment [5], heat treatment [10], and organo-solvent treatment [6].

A high-frequency current flowing through a piezoelectric element with sound waves above the audible frequency creates ultrasonic waves. They can also be created by changing the magnetic field against a magnetic object, a method used in various industrial fields [12-14].

Although there have been few attempts to treat wood with ultrasound, Tanaka et al. reported that ultrasound increased Douglas fir (Pseudotsuga menziesii) permeability in both the radial and tangential directions due to ultrasonic pit de-aspiration or destruction [15]. The ultrasonic treatment removed intracellular lumen impurities in the direction of the wood cells, which improved the pores' air permeability (the pores are the fluid pathway between the wood cells) [15]. 
Previous studies found that increasing wood permeability leads to an increase in sound absorption coefficient. Therefore, we expect ultrasonic treatment of wood to cause an increase in sound absorption performance.

In this study, Malas from Papua New Guinea (Homalium foetidum) was selected, which is popular because it is relatively inexpensive among Southeast Asian timber used in Korea [16]. The changes in gas permeability and sound absorption coefficient between untreated and ultrasonic-treated Malas were investigated.

\section{Materials and methods}

\section{Sample preparation}

Malas (Homalium foetidum) timbers were supplied from Jeonil Timber Co., Ltd in Korea. They cut logs into 20 cylindrical specimens with a $2.9 \mathrm{~cm}$ diameter and $1 \mathrm{~cm}$ cross-sectional thickness (Fig. 1). They were exposed to standard room conditions for one month. Their air-dried specific gravity and MC (moisture content) were 0.8 and $12 \%$, respectively.

\section{Ultrasonic treatment}

We added $200 \mathrm{ml}$ of water into an ultrasonic cleaner (model: SD-80H, SungDong Ultrasonic Co. Ltd.), and 20 cylindrical specimens were treated for about $25 \mathrm{~min}$ with a $40 \mathrm{kHz}$ ultrasonic wave frequency and $50 \mathrm{~W}$ output power. After ultrasonic treatment, the specimens were dried at $40{ }^{\circ} \mathrm{C}$ for $8 \mathrm{~h}$ in a dryer and then equilibrated to the laboratory environment for $24 \mathrm{~h}$. The MC of cylindrical specimens was similar between untreated and ultrasonic-treated samples.

\section{Gas permeability measurements}

Gas permeability of untreated and ultrasonic-treated cylindrical specimens was measured by a capillary flow porometer (model: CFP-1200AEL, Porous Material Inc., Ithaca, NY, U.S.A). It measured the flow rate through the sample while pressing the sample vertically from atmospheric pressure to $1 \mathrm{~atm}$.

Capillary flow porometer calculated automatically the Darcy permeability constant (K) using Eq. (1) and Eq. (2) [17]:

$$
\begin{aligned}
& k=\frac{Q / A}{\Delta P / L} \\
& K=1.013 \times 10^{8} \mathrm{k \eta}
\end{aligned}
$$

$K=$ specific permeability (Darcy), $k=$ permeability $\left(\mathrm{cm}^{3} /\right.$ dyne $\mathrm{s}), \eta=$ viscosity of air $\left(=1.81 \times 10^{-4}\right.$ dyne $\left.\mathrm{s} / \mathrm{cm}^{2}\right)$, $Q=$ gas flow rate $\left(\mathrm{cm}^{3} / \mathrm{s}\right), A=$ cross sectional area of the specimen $\left(\mathrm{cm}^{2}\right), \Delta P=$ pressure difference $\left(\right.$ dyne $\left./ \mathrm{cm}^{2}\right)$, $L=$ length of the specimen $(\mathrm{cm})$.

We sealed the samples' side surfaces with a silicon O-ring to prevent air leakage from the edges and estimated the same gas permeability direction both untreated and ultrasonic-treated cylindrical specimens.

\section{Sound absorption coefficient measurements}

Sound absorption coefficients of untreated and ultrasonic-treated cylindrical specimens were measured according to ISO 10534-2 using the two microphone transfer function method with an impedance tube kit (model: type 4706, B\&K Company, nærum, Denmark), pulse analysis software, and a spectrum analyzer (model: type 3560, B\&K Company, nærum, Denmark) [18]. We used a silicone O-ring to prevent experimental error from the air gap between the test specimen and impedance tube and, using the same direction for both, estimated the gas permeability before and after treatment. We used a frequency range of $50 \mathrm{~Hz}$ to $6.4 \mathrm{kHz}$. Prior to ultrasonic treatment, atmospheric pressure, temperature, relative humidity, sound velocity, air density, and acoustic impedance were $1030 \mathrm{hPa}, 20.20{ }^{\circ} \mathrm{C}, 35 \%, 343.35 \mathrm{~m} / \mathrm{s}, 1.221 \mathrm{~kg} /$ $\mathrm{m}^{3}$, and $419.2 \mathrm{~Pa} /(\mathrm{m} / \mathrm{s})$, respectively. After treatment, conditions were $1021 \mathrm{hPa}, 25.4{ }^{\circ} \mathrm{C}, 26 \%, 346.38 \mathrm{~m} / \mathrm{s}$, $1.189 \mathrm{~kg} / \mathrm{m} 3$ and $411.9 \mathrm{~Pa} /(\mathrm{m} / \mathrm{s})$, respectively.

\section{Cross-sectional surface observations}

To observe microscopic feature changes caused by ultrasonic treatment, we cut untreated and treated specimens into $7 \mathrm{~mm}$ (radial) $\times 7 \mathrm{~mm}$ (tangential) $\times 6 \mathrm{~mm}$ (longitudinal) samples using a microtome (model: HM400S, Microm GmbH, Germany). We coated the specimens with gold ions using an ion sputter-coater (model: SCM,

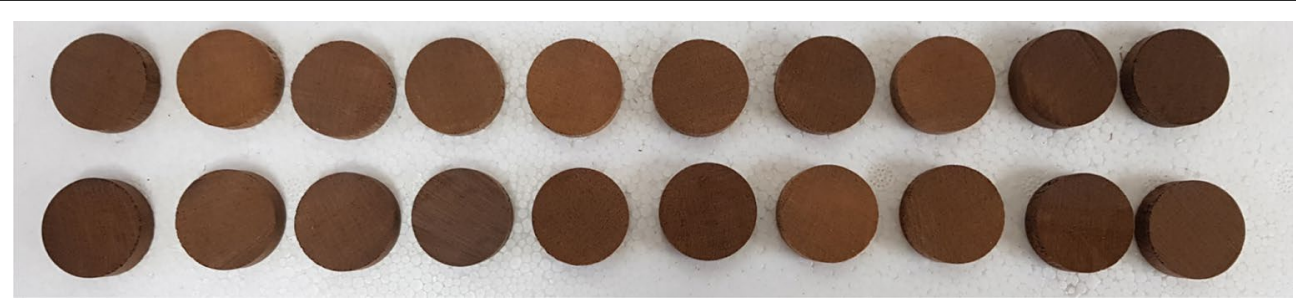

Fig. 1 Malas sample preparation 


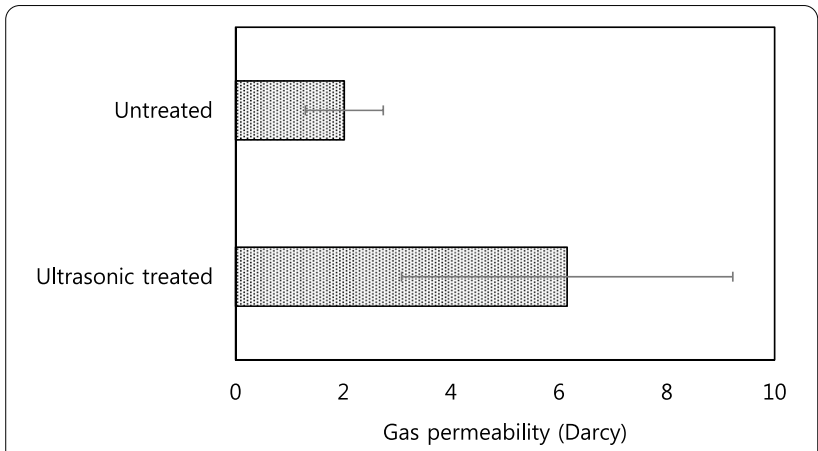

Fig. 2 Darcy permeability constant for untreated and ultrasonic-treated Malas (error bar is SD)

Emcrafts, Korea) and observed the samples at a $20 \mathrm{kV}$ acceleration voltage and $200 \times$ magnification using a scanning electron microscope (SEM) (model: Genesis-1000, Emcrafts, Korea).

\section{Results and discussion Gas permeability}

Figure 2 shows gas permeability changes between untreated and ultrasonic-treated Malas. A change of 2.02 (standard deviation SD 0.72) was measured for untreated wood and 6.15 (SD 3.07) for ultrasound-treated wood. Paired $t$ test was performed to statistically determine the difference in gas permeability between untreated and ultrasonic-treated cylindrical specimens. Results of $t=-6.709$ and $p=0.000$ indicate a statistically significant difference in gas permeability before and after ultrasonic treatment. The treated wood's gas permeability was 3.04 times higher than that of the control. Tanaka et al. found the permeability in the radial and tangential directions to increase 15.3 and 16.2 times when treated with $20 \mathrm{kHz}$ ultrasound for $80 \mathrm{~min}$ [15]. These results show that the ultrasonic sound treatment influences permeability changes [15]. The high permeability increases are due to the Malas's many diffuse, porous, large-diameter vessels on the cross-sectional surface (Figs. 4 and 5) which leads them to behave as through pores. Kang et al. reported that vessel and the single perforation plate of hardwood behave as through pores that are effective for sound absorption [19].

This is because the ultrasonic treatment removed impurities present in the vessels.

\section{Sound absorption coefficient}

Figure 3 shows the average sound absorption coefficients calculated between $50 \mathrm{~Hz}$ and $6.4 \mathrm{kHz}$ for the untreated and ultrasonic-treated Malas specimens.

The untreated specimen's average sound absorption coefficient is 0.23 (SD 0.02) and NRC (noise reduction

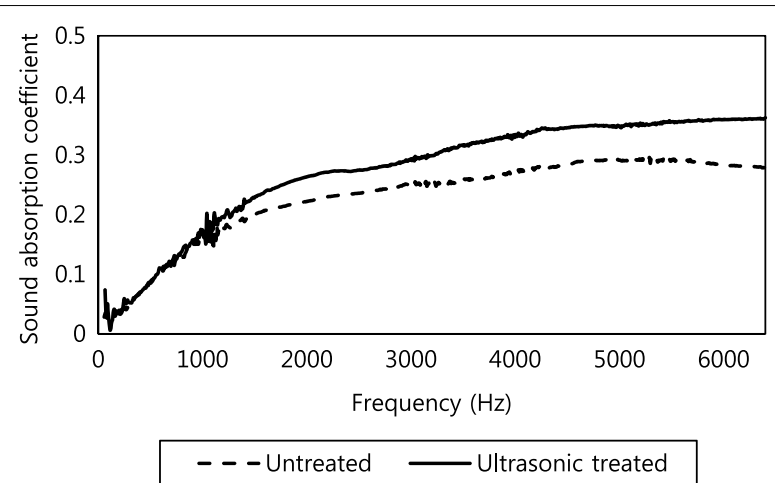

Fig. 3 Average sound absorption coefficients of the untreated and ultrasonic-treated Malas

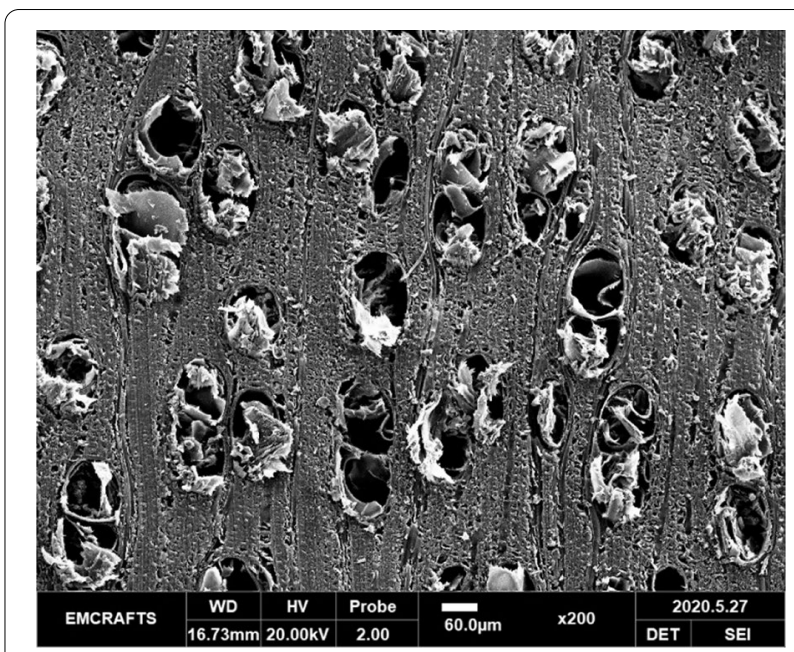

Fig. 4 SEM image of the cross-sectional surface of untreated Malas

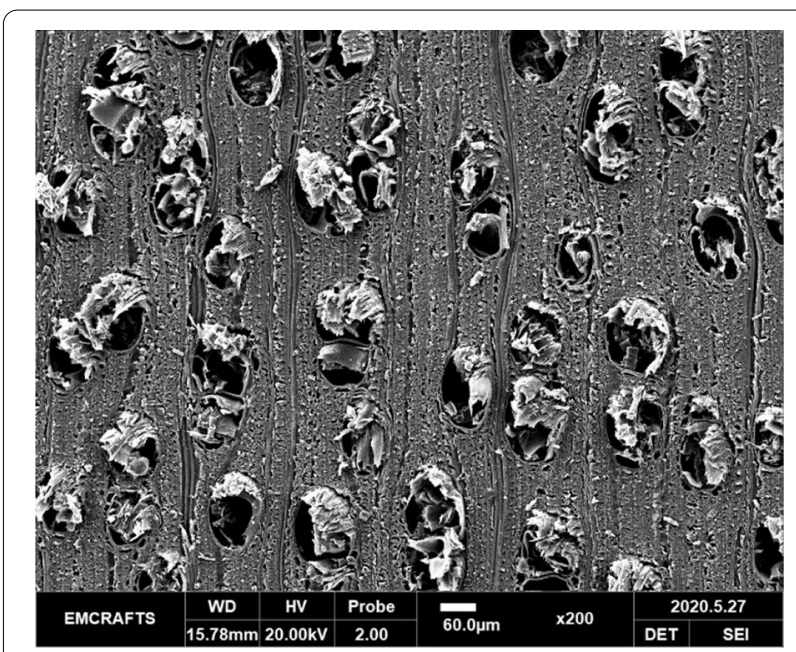

Fig. 5 SEM image of the cross-sectional surface of ultrasound-treated Malas 
coefficient: average value of sound absorption coefficient value at $250,500,1000$, and $2000 \mathrm{~Hz}$ ) is 0.13 (SD 0.01 ). The ultrasonic-treated specimen's average sound absorption coefficient is 0.28 (SD 0.06) and NRC is 0.14 (SD 0.02), and paired t test was performed to statistically determine the difference in average sound absorption coefficient between untreated and ultrasonictreated cylindrical specimens. Results of $t=-3.232$ and $p=0.002$ indicate a significant difference in average sound absorption coefficient before and after ultrasonic treatment.

The sound absorption coefficient increased with frequency for both the untreated and ultrasonic-treated specimen. The sound absorption coefficient of the porous material showed a tendency to increase at high frequencies, and porous material with a high specific gravity and small porosity exhibited low sound absorption characteristics [20]. The Malas's sound absorption coefficient was only $10 \%$ at low frequencies, but over $2 \mathrm{kHz}$, it reached 0.3 to 0.5 . These are relatively high values and demonstrate that this wood could be used as sound-absorbing material. A large amount of diffuse porous vessels with little tylosis formation can be seen in Malas's cross section. The void volume of hardwood can be anatomically classified into vessels, perforation plates, and pit. In previous studies, void volume of wood was classified into through pores, blind pores, and closed pores [8-10]. This is in accordance with IUPAC's definition of physical pore types of solid porous material. Since both ends are open, a pore through which the fluid can flow is defined as a through pore, a pore with one side blocked as a blind pore, and a pore impregnated within the material as a closed pore [21]. The size of the through pore affects wood permeability $[8-10,22]$, and the sound absorption coefficient increases when the through pore porosity increases.

We found that the sound absorption coefficient increased after ultrasonic treatment, most effectively in the high-frequency range. The ultrasonic forces enlarged the through pore diameter and eliminated obstacles on the wood's cross-sectional surface.

The sound absorption coefficient did not increase in proportion to the gas permeability increase. Other factors, in addition to gas permeability, can affect wood cross-sectional permeability. Further studies are needed in this area.

\section{Anatomical features}

As shown in Figs. 4 and 5, we confirmed that Malas contains a typical wood-diffuse porous structure. We observed many vessels on the cross-sectional surface, which led to the high sound absorption coefficient.
Wood-diffuse porous structures seem to absorb sound energy effectively [23].

Although the ultrasonic-treated specimens showed a 2.87 times gas permeability increase, we saw little difference in the cross-sectional SEM images. SEM did not show any internal pathway changes related to ultrasonic treatment [10].

\section{Conclusion}

We measured changes to gas permeability and sound absorption coefficient using an ultrasonic treatment on Malas wood. We obtained the following conclusions:

1. The ultrasonic treatment increased gas permeability in the fiber direction of a Malas cross section by 2.87 times.

2. The ultrasonic treatment increased the sound absorption coefficient by $19.74 \%$.

\begin{abstract}
Abbreviations
K: Specific permeability; $k$ : Permeability; $\eta$ : Viscosity of air; Q: Gas flow rate; $A$ : Cross-sectional area of the specimen; $\triangle P$ : Pressure difference; $L$ : Length of the specimen; MC: Moisture content; NRC: Noise reduction coefficient: average value of sound absorption coefficient value at 250, 500, 1000, and $2000 \mathrm{~Hz}$; SD: Standard deviation.
\end{abstract}

\section{Acknowledgements}

This research was supported by the Basic Science Research Program through the National Research Foundation of Korea (NRF) funded by the Ministry of Education (NRF-2019R1/1A3A02059471) and was supported under the framework of an international cooperation program managed by the NRF of Korea (NRF-2020K2A9A2A08000181). The authors are thankful to the "Leaders in Industry-University Cooperation+ Project," supported by the Ministry of Education and NRF of Korea.

\section{Authors' contributions}

CWK: Conceptualization, Methodology, and Writing —original draft. ESJ: Experiment, Data analysis, and Writing-original draft. NHL: Supervision and Writing —review \& editing, SSJ and ML: Writing — review \& editing. All authors read and approved the final manuscript.

\section{Funding}

No Funding.

\section{Availability of data and materials \\ Not applicable.}

\section{Competing interests}

The authors declare that they have no competing interests.

\footnotetext{
Author details

${ }^{1}$ Department of Housing Environmental Design, and Research Institute of Human Ecology, College of Human Ecology, Jeonbuk National University, Jeonju 54896, South Korea. ${ }^{2}$ Department of Wood Science \& Technology, College of Agriculture \& Life Sciences, Jeonbuk National University, Jeonju 54896, South Korea. ${ }^{3}$ Department of Forest Products, College of Agriculture \& Life Sciences, Chungnam National University, Daejeon 34134, South Korea. ${ }^{4}$ Department of Forest Products, National Institute of Forest Science, Seoul 02455, South Korea.
} 
Received: 5 August 2020 Accepted: 25 December 2020

Published online: 31 January 2021

\section{References}

1. Petty J, Puritch G (1970) The effects of drying on the structure and permeability of the wood of Abies grandis. Wood Sci Techno 4(2):140-154

2. Schneider A, Wagner $L$ (1974) Bestimmung der Porengrößenverteilung in Holz mit dem Quecksilber-Porosimeter. HOLZ als Roh-und Werkstoff 32(6):216-224

3. Bertaud F, Holmbom B (2004) Chemical composition of earlywood and latewood in Norway spruce heartwood, sapwood and transition zone wood. Wood Sci Techno 38(4):245-256

4. Rice RW, D'Onofrio M (2007) Longitudinal gas permeability measurements from eastern white pine, red spruce, and balsam fir. Wood Fiber Sci 28(3):301-308

5. Kang C-W, Kim G-C, Park H-J, Lee N-H, Kang W, Matsumura J (2010) Changes in permeability and sound absorption capability of yellow poplar wood by steam explosion treatment. J Fac Agric Kyushu Univ 55(2):327-332

6. Kang C-W, Jang E-S, Jang S, Kang H-Y, Li C, Choi I-G (2018) Changes of Air Permeability and Moisture Absorption Capability of the Wood by Organosolv Pretreatment. J Korean Wood Sci Technol 46(6):637-644

7. Kanagaw Y (1992) Improvement of dryability by local steam explosion for Japanese cedar. Paper presented at the IUFRO Internatinal Wood Drying Conference, Vienna, Austria, 1992

8. Jang E-S, Kang C-W, Jang S-S (2019) Pore characterization in cross section of yellow poplar (Liriodendron tulipifera) wood. J Korean Wood Sci Technol 47(1):8-20

9. Jang E-S, Yuk J-H, Kang C-W (2020) An experimental study on change of gas permeability depending on pore structures in three species (hinoki, Douglas fir, and hemlock) of softwood. J Wood Sci 66(1):1-12

10. Jang E-S, Kang C-W (2019) Changes in gas permeability and pore structure of wood under heat treating temperature conditions. J Wood Sci 65(1):1-9

11. Kang C, Kang W, Chung W, Matsumura J, Oda K (2008) Changes in anatomical features, air permeability and sound absorption capability of wood induced by delignification treatment. J Fac Agric Kyushu Univ 53(2):479-483
12. Arefi-Oskoui S, Khataee A, Safarpour M, Orooji Y, Vatanpour V (2019) A review on the applications of ultrasonic technology in membrane bioreactors. Ultrason Sonochem 58:104633

13. Yao Y, Pan Y, Liu S (2020) Power ultrasound and its applications: A state-ofthe-art review. Ultrason Sonochem 62:104722

14. Dong Z, Delacour C, Mc Carogher K, Udepurkar AP, Kuhn S (2020) Continuous ultrasonic reactors: design, mechanism and application. Materials (Basel) 13:2

15. Tanaka T, Avramidis S, Shida S (2010) A preliminary study on ultrasonic treatment effect on transverse wood permeability. Maderas Ciencia y tecnología 12(1):03-09

16. Seo B-S (2019) http://www.imwood.co.kr/news/articleView.html?idxno $=23029$. Accessed 7-Sep 2020 [in Korean]

17. Kang H-Y, Lu J (2005) Comparison of longitudinal liquid permeability of Pinus koraiensis sapwood treated by steaming and various drying methods. J Korean Wood Sci Technol 33(6):17-24

18. ISO11534-2 (2001) Acoustics-Determination of sound absorption coefficient and impedance in impedance tubes-Part 2 transfer-function method. International Organization for Standardization, Geneva, Switzerland

19. Kang C-W, Jang E-S, Jang S-S, Cho J-I, Kim N-h (2019) Effect of Heat Treatment on the Gas Permeability, Sound Absorption Coefficient, and Sound Transmission Loss of Paulownia tomentosa Wood. J Korean Wood Sci Technol 47(5):644-654

20. Cao L, Fu Q, Si Y, Ding B, Yu J (2018) Porous materials for sound absorption. Composites Communications 10:25-35

21. Rouquerol J, Avnir D, Fairbridge C, Everett D, Haynes J, Pernicone N, Ramsay J, Sing K, Unger K (1994) Recommendations for the characterization of porous solids (Technical Report). Pure Appl Chem 66(8):1739-1758

22. Jang E-S, Kang C-W, Kang H-Y, Jang S-S (2018) Sound Absorption Property of Traditional Korean Natural Wallpaper (Hanji). J Korean Wood Sci Technol 46(6):703-712

23. Kang C-W, Lee Y-H, Kang H-Y, Kang W, Xu H, Chung W-Y (2011) Radial variation of sound absorption capability in the cross sectional surface of yellow poplar wood. J Korean Wood Sci Technol 39(4):326-332

\section{Publisher's Note}

Springer Nature remains neutral with regard to jurisdictional claims in published maps and institutional affiliations.

\section{Submit your manuscript to a SpringerOpen ${ }^{\circ}$ journal and benefit from:}

- Convenient online submission

- Rigorous peer review

- Open access: articles freely available online

- High visibility within the field

- Retaining the copyright to your article

Submit your next manuscript at springeropen.com 